(C) 2022, The Authors. Published by Elsevier Inc. and Fass Inc. on behalf of the American Dairy Science Association ${ }^{\circledR}$. This is an open access article under the CC BY license (http://creativecommons.org/licenses/by/4.0/).

\title{
Genome-wide association study using haplotype libraries and repeated-measures model to identify candidate genomic regions for stillbirth in Holstein cattle
}

\author{
P. A. S. Fonseca, () F. S. Schenkel, (1) and A. Cánovas* (i) \\ Centre for Genetic Improvement of Livestock, Department of Animal Biosciences, University of Guelph, Guelph, ON N1G 2W1, Canada
}

\begin{abstract}
Reduced fertility is one of the main causes of economic losses on dairy farms, resulting in economic losses estimated at $\$ 938$ per stillbirth case in Holstein herds. The identification of genomic regions associated with stillbirth could help to develop better management and breeding strategies aimed to reduce the frequency of undesirable gestation outcomes. Here, 10,570 cows and 50,541 birth records were used to perform a haplotypebased GWAS. A total of 41 significantly associated pseudo-SNPs (haplotypes within haplotype blocks converted to a binary classification) were identified after Bonferroni adjustment for multiple tests. A total of 117 positional candidate genes were annotated within or close (in a $200-\mathrm{kb}$ interval) to significant pseudo-SNPs (haplotype blocks). The guilt-by-association functional prioritization identified 31 potential functional candidate genes for reproductive performance out of the 117 positional candidate genes annotated. These genes play crucial roles in biological processes associated with pregnancy persistence, fetus development, immune response, among others. These results helped us to better understand the genetic basis of stillbirth in dairy cattle and may be useful for the prediction of stillbirth in Holstein cattle, helping to reduce the related economic losses caused by this phenotype.
\end{abstract}

Key words: functional candidate gene, genome-wide association study, haplotype, Holstein, stillbirth

\section{INTRODUCTION}

Reduced fertility is one of the main causes of economic losses on dairy farms. Stillbirth is defined as calf death just before or during parturition, or within

Received June 29, 2021.

Accepted September 24, 2021.

*Corresponding author: acanovas@uoguelph.ca
$48 \mathrm{~h}$ after birth (Berglund et al., 2003). The financial losses are estimated to be $\$ 938$ per stillbirth case in Holstein herds (Mahnani et al., 2018). The frequency of stillbirth events is an indicator of welfare shortfalls in dairy herds and must be controlled in the herds. Usually, genetic studies investigate stillbirth using only the first birth record due to the higher heritability $\left(\mathrm{h}^{2}\right)$ of first parities $\left(\mathrm{h}^{2}=0.11\right)$ compared with later parities $\left(\mathrm{h}^{2}=0.01\right.$; Guarini et al., 2018). However, the same cow may show different outcomes in different gestations. Therefore, evaluation of a single time point may provide a biased indication of the genetic causes of stillbirth. Consequently, the use of statistical models that consider all the birth records of the cows is an interesting alternative to study the genetic causes of stillbirth events. The identification of genomic regions associated with stillbirth could help to develop better management and breeding strategies aimed to reduce the frequency of this undesirable gestation outcome. The use of haplotype libraries for GWAS can increase detection power of candidate regions due to an increased genetic variation captured by haplotypes and the finer mapping of the candidate regions (Barendse, 2011; Wu et al., 2014; Chen et al., 2018; Id-Lahoucine et al., 2019; Feitosa et al., 2021). In livestock species, the haplotype and repeated record approached are not widely applied due to several factors, such as the complexity to estimate haplotype blocks, low SNP panel density, and the common focus on first-parity cows.

Therefore, the objectives of this work were (1) to identify candidate genomic regions associated with stillbirth using a haplotype library and a repeated measures model and (2) to prioritize potential functional candidate genes associated with biological processes associated with stillbirth in dairy cattle. The combination of both approaches, the use of repeated measures and haplotype-based association studies, is hypothesized to help identify candidate regions for stillbirth in the cattle genome, providing a better understanding of the biological basis of reproduction in dairy cattle. 


\section{MATERIALS AND METHODS}

\section{Phenotypic and Genotypic Data}

The phenotypic and genotypic information of 61,264 cows were provided by Lactanet. A total of 136,282 stillbirth records from Holstein cows collected between April 1997 and June 2019 were analyzed. The stillbirth events were defined as a calf born dead or a calf that died in the first $48 \mathrm{~h}$ after calving. All the animals were imputed and phased for the 50,925 SNP markers composing the BovineSNP50K BeadChip (Illumina Inc.) array using the FImpute software version 2.2 (Sargolzaei et al., 2011). The original SNP panels used to genotype the animals before imputation and the number of animals per panel are shown in Supplemental Table S1 (https://data.mendeley.com/datasets/ nnp5hdy9cv/1; Fonesca et al., 2021). All phenotypic and genotypic data used in this study were obtained from pre-existing databases. Therefore, no animal care committee approval was necessary for the purposes of this study.

\section{Haplotype Block Detection and Pseudo-SNP Encoding}

The haplotype blocks were detected using the Haploview software version 4.2 (Barrett et al., 2005). The command line option from Haploview was used, and the haplotype blocks were called using the Gabriel blocks algorithm (Gabriel et al., 2002). Only autosomal markers with Hardy-Weinberg equilibrium test probability threshold $>10^{-6}$, minor allelic frequency $>0.01$, and maximum distance between markers equal to $2 \mathrm{~kb}$ were kept for the analyses. In addition, only haplotypes with a frequency higher than 0.01 were retained for further analyses.

The haplotype blocks were mapped against the phased genotypes, and the 2 individual haplotypes in a haplotype block were extracted for each individual. Subsequently, the number of copies of each haplotype within each haplotype block was counted for each individual, creating a pseudo-SNP matrix (haplotypes within haplotypic blocks converted to a binary classification). The pseudo-SNP matrix was then used in the GWAS, and the association of each pseudo-SNP with the stillbirth events was tested as described below.

\section{Haplotype-Based GWAS Using Repeated Measures for Stillbirth}

The software ASReml 4.1 (Gilmour et al., 2015) was used to identify the pseudo-SNPs associated with the stillbirth events. For this analysis, only cows with 3 or more records were retained (i.e., 10,570 cows and 50,541 records). The statistical model used was as follows:

$$
\begin{aligned}
y_{i j k l m n o p q}= & \mu+C s_{i}+C s e x_{j}+C a_{k}+\text { Psnp }_{l}+H Y S_{m} \\
& +C a d d_{n}+S S_{o}+P e_{p}+e_{i j k l m n o p q}
\end{aligned}
$$

where $y_{i j k l m n o p q}$ is the $q$ th phenotypic observation of the $n$th cow; $\mu$ is the overall mean, $C s_{i}$ is the effect of $i$ th calf size, $C s e x_{j}$ is the effect of the $j$ th calf sex, $C a_{k}$ is the effect of the $k$ th cow age class $(<36,36-50,50-63$, $63-75, \geq 75 \mathrm{mo}$ ), and $P s n p_{l}$ is the allele substitution effect of the lth pseudo-SNP effect, which were all treated as fixed effects; $H Y S_{m}$ is the random effect of the $m$ th herd-year-season, $\mathrm{Cadd}_{n}$ is the random additive genetic effect of the $n$th cow, and $S S_{o}$ is the random additive genetic effect of the oth service sire. Additionally, $P e_{p}$ is the random permanent environment effect of the $p$ th cow with records, and $e_{i j k l m n o p q}$ is the random residual effect associated with the qth phenotypic observation. The cow age classes were defined as described by Jamrozik et al. (2016). The additive relationship matrix based on pedigree (21,278 animals, from which 11,436 were parents, going back 1 generation) was used for modeling the covariance among additive polygenic animal effects. The significantly associated pseudo-SNPs were identified using Bonferroni adjustment for multiple tests at a $5 \%$ genome-wide significance level.

\section{Functional Candidate Genes Search}

The positional candidate genes (genes annotated within and in a 200-kb interval, $100 \mathrm{~kb}$ downstream and upstream from the start and end haplotypes coordinates) were annotated using the $\mathrm{R}$ package GALLO (Fonseca et al., 2020a). The cattle QTL annotated were annotated using the haplotype coordinates, without additional intervals due to the extensive length of some QTL, from the Animal QTLdb database (https://www .animalgenome.org/cgi-bin/QTLdb/index; Hu et al., 2019). The QTL enrichment analysis was performed using GALLO as described by Fonseca et al. (2020a). A guilt-by-association approach was performed to identify potential functional candidate genes (Fonseca et al., 2020b; Martins de Carvalho et al., 2020; Sweett et al., 2020; Lam et al., 2021). Briefly, a trained list containing genes associated with stillbirth and pregnancy persistence was obtained from GUILDify (Guney et al., 2014), using the following list of keywords: stillbirth, pregnancy, and pregnancy loss. In the current study, the top 100 genes with the highest guild scores were selected to compose the trained list. Subsequently, ToppGene suit (Chen et al., 2009) was used to perform a functional annotation from both trained list and posi- 
tional candidate gene list annotated from the significant haplotypes. A multivariate analysis was performed to associate the functional profile of each positional candidate gene with the functional profile of the trained list. The functional profile was created using information from gene ontology terms for the 3 main categories of molecular function, biological process, and cellular component; human and mouse phenotypes; metabolic pathways; Pubmed publications; and diseases from ToppGene database (Chen et al., 2009; Cánovas et al., 2012; Fonseca et al., 2018). An overall $P$-value was calculated using a statistical meta-analysis. Subsequently, the genes with a significant $P$-value, after a $5 \%$ false discovery rate adjustment for multiple tests, were selected as prioritized genes. The complete description of the meta-analysis to calculate the final $P$-value is available in Chen et al. (2009).

\section{RESULTS}

\section{Phenotypic Data Distribution}

The data set used for the GWAS was composed of 50,541 birth records from 10,570 Holstein cows (cows with 3 or more birth records). A frequency of $11.47 \%$ stillbirth cases (5.796 cases) was identified among the 50,541 birth records. An average $( \pm \mathrm{SD})$ of $4.78 \pm 1.31$ records per individual, with a maximum of 13 records, was observed in this data set. The mean of stillbirth events per individual was $0.55( \pm 0.59)$, with a minimum number of stillbirth events of 0 and a maximum of 5 . The number of animals by number stillbirth events was as follows: 5,285 animals with 0 events, 4,808 animals with 1 event, 445 animals with 2 events, 31 animals with 3 events, and 1 animal with 5 events.

\section{Haplotypes Significantly Associated with Stillbirth}

An average of 60.8 haplotype blocks were identified per chromosome. The chromosomes BTA1 and BTA28 had the largest and smallest number of haplotype blocks with 145 and 16, respectively (Supplemental Table S2, https: / / data.mendeley.com/datasets/nnp5hdy9cv/ 1; Fonesca et al., 2021). The distribution of number of markers and haplotype length (in $\mathrm{kb}$ ) are shown in Figure 1. The maximum average number of markers per haplotype block was identified in BTA8 (4.9) and the maximum average length was identified in BTA5 (198.9 $\mathrm{kb})$. A total of 41 significantly associated pseudo-SNPs were identified after Bonferroni correction (Figure 2 and Supplemental Table S3, https://data.mendeley .com/datasets/nnp5hdy9cv/1; Fonesca et al., 2021). A total of 117 genes were annotated within the significant haplotypes (Supplemental Table S4, https://data .mendeley.com/datasets/nnp5hdy9cv/1; Fonesca et al., 2021).

\section{Functional Annotation of Candidate Regions}

There were 31 genes, out of 117 genes annotated within the significant haplotypes, significantly associated with the functional profile of the trained list in the guilt-by-association analysis. A total of 20 unique pseudo-SNPs were mapped within the coordinates of these 31 functional candidate genes. The functional profile of the trained list and the prioritization results can be found in Supplemental Tables S5 and S6 (https://data .mendeley.com/datasets/nnp5hdy9cv/1; Fonesca et al., 2021), respectively. The trained list was composed of genes directly associated with the regulation of fertility and embryonic development, substantiating the group of genes chosen to compose the trained list. The list of prioritized genes and each one of the haplotypes mapped within the coordinates of the functional candidate genes are presented in Table 1.

\section{Enrichment Analysis for Quantitative Trait Loci Within the Candidate Genomic Regions}

The QTL annotation analysis using the list of 41 significantly associated pseudo-SNPs (Supplemental Table S7, https://data.mendeley.com/datasets/nnp5hdy9cv/ 1; Fonesca et al., 2021) indicated that the majority of the QTL annotated in these regions are mainly related to reproductive processes, accounting for $33.5 \%$ of all QTL classes (Figure 3). Among them, "calving ease," "interval to the first estrus after calving," and "interval from first to last insemination" are the most frequently annotated traits within those candidate regions. Additionally, "stillbirth" and "stillbirth (maternal)" QTL were also previously reported within the candidate regions identified in the present study.

The list of QTL annotated within the significantly associated haplotypes was also used to perform an enrichment analysis to test if candidate genomic coordinates were associated with specific traits more than expected by chance. The enrichment analysis was performed for each trait annotated using the Animal QTLdb database and the R package GALLO for each chromosome individually, helping to reduce the specialization bias observed on some chromosomes such as the BTA14 for milk production (Bennewitz et al., 2004). The QTL enrichment analysis indicated a total of 45 enriched QTL (Supplemental Table S8, https://data.mendeley .com/datasets/nnp5hdy9cv/1; Fonesca et al., 2021), from which 13 were reproduction-related QTL (Figure 4). The BTA5 and BTA14 were those with the largest number of reproduction-related QTL identified as 

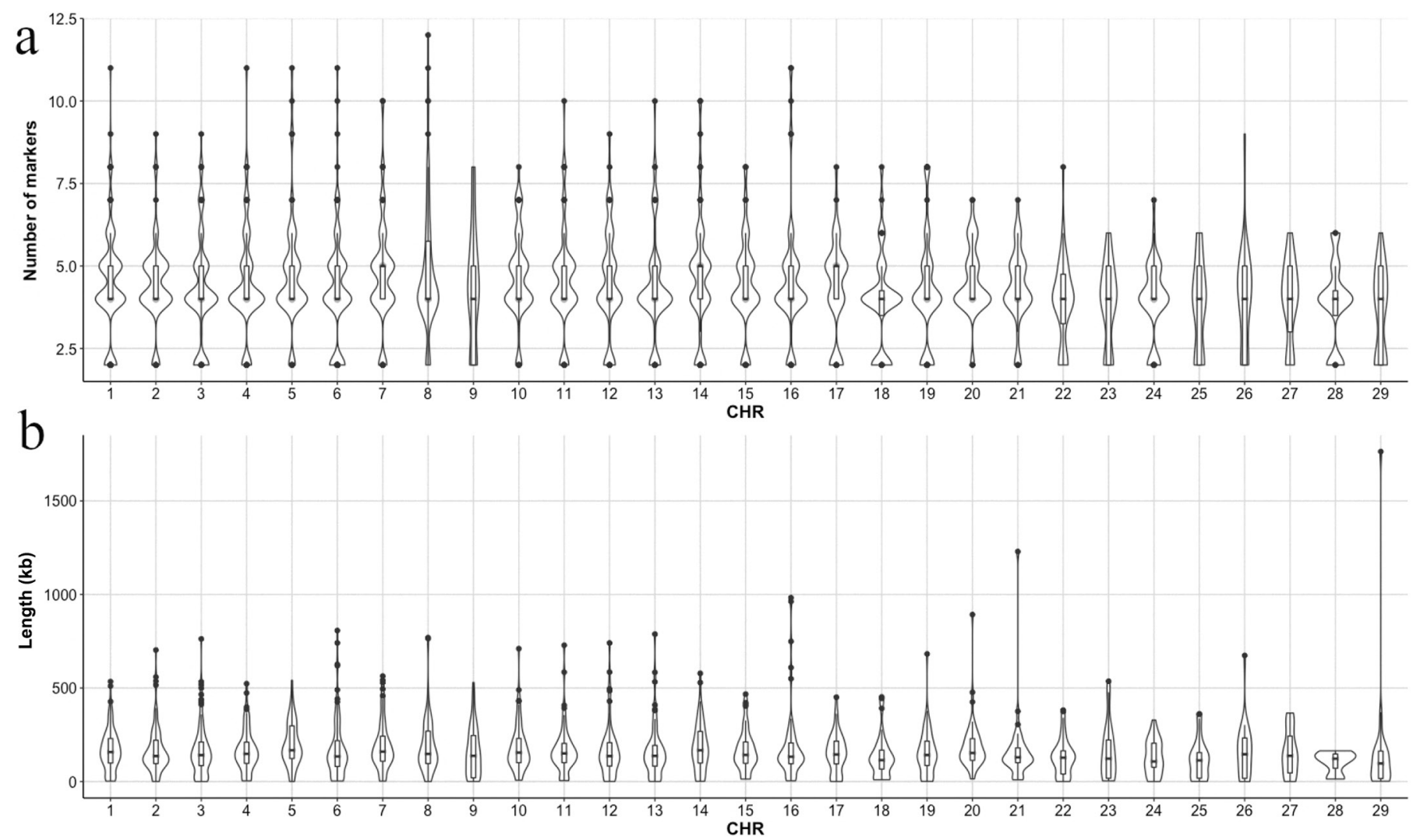

Figure 1. Violin plots showing the haplotype block distribution for number of markers in the block (a) and its length in kb (b) per chromosome (CHR). The shapes around the boxplots represent the kernel density for the data distribution, and the dots represent records above the 1.5 interquartile range threshold.

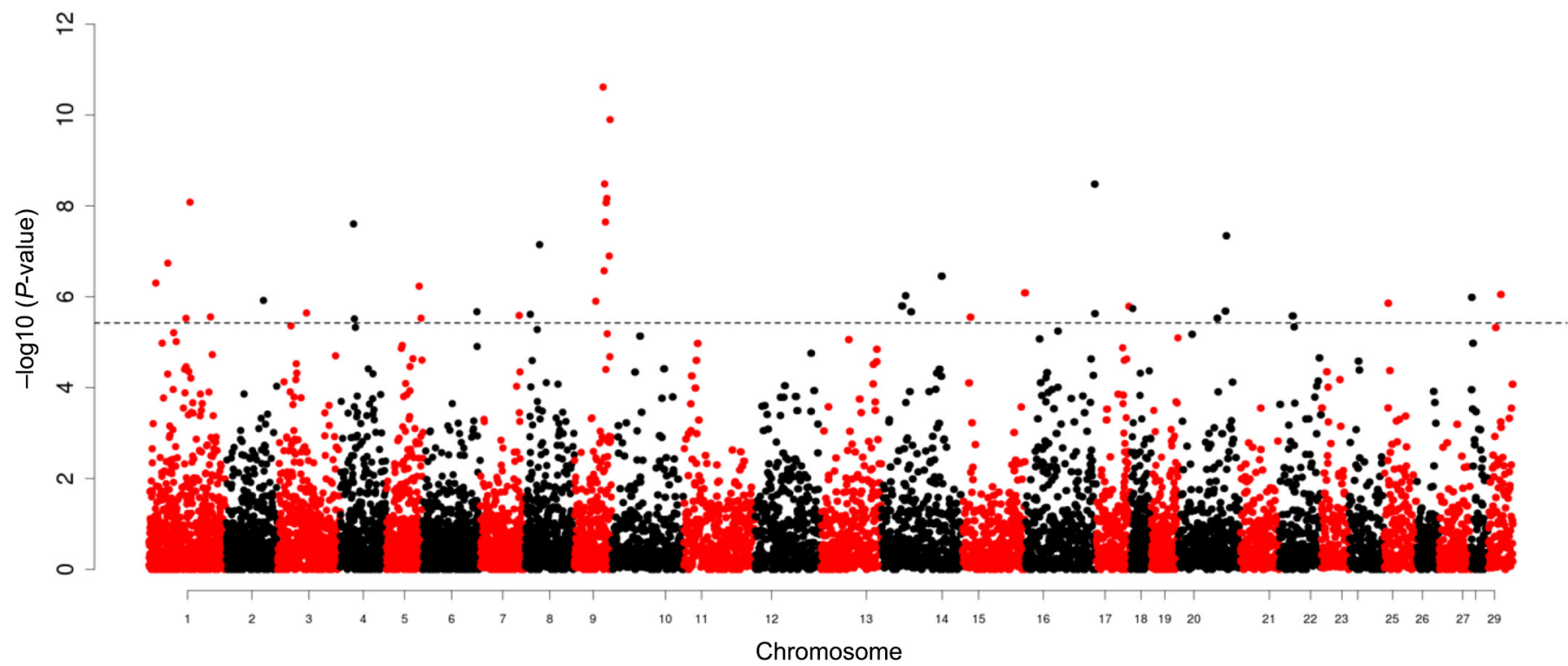

Figure 2. Manhattan plot for the GWAS using haplotype libraries for stillbirth. The y-axis presents the nonadjusted $P$-values, and the $\mathrm{x}$-axis shows the chromosomes. The dashed horizontal line delimits the Bonferroni adjustment for multiple tests threshold. 
Fonseca et al.: HAPLOTYPE ASSOCIATION FOR STILLBIRTH IN HOLSTEINS

1318

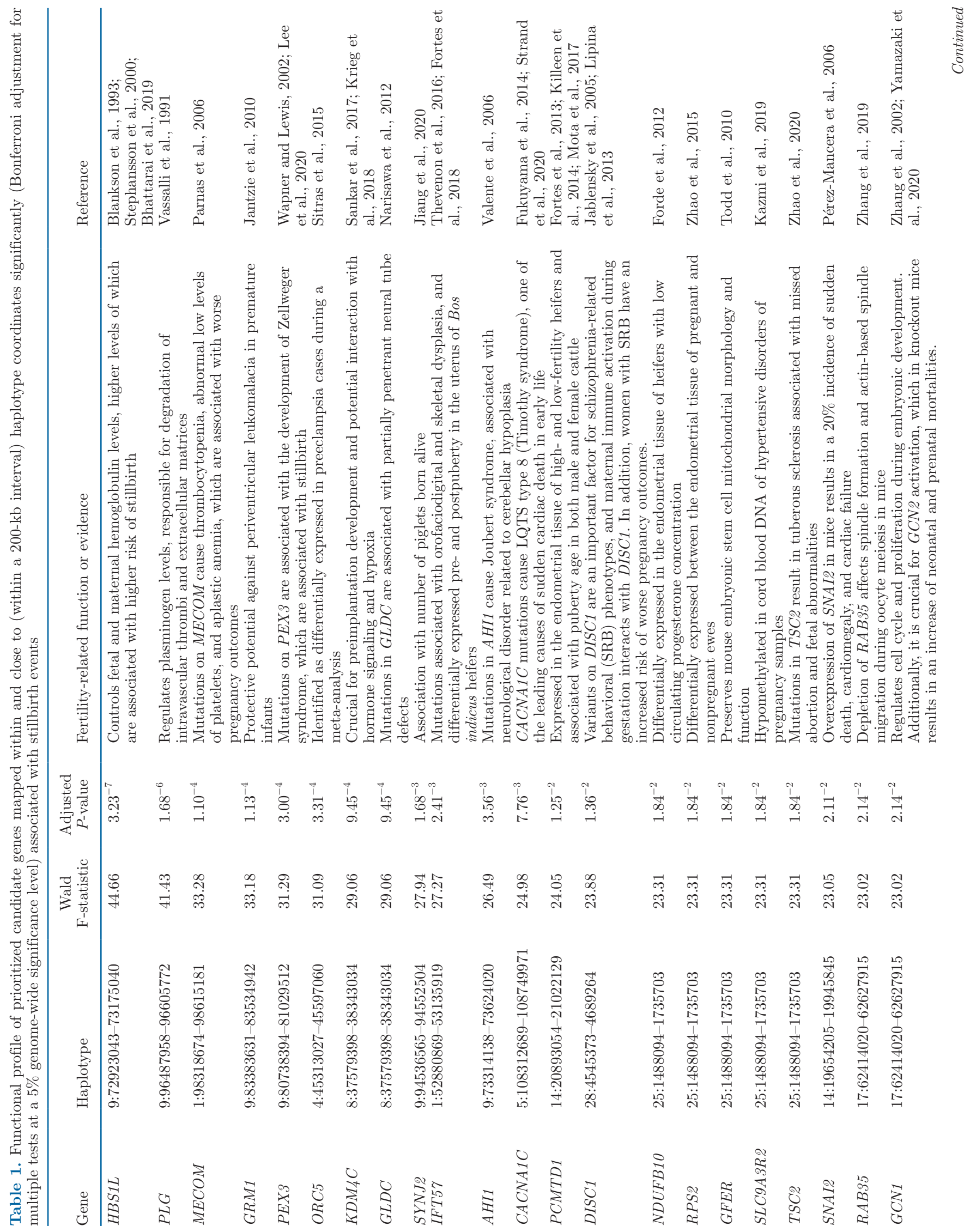

Journal of Dairy Science Vol. 105 No. 2, 2022 


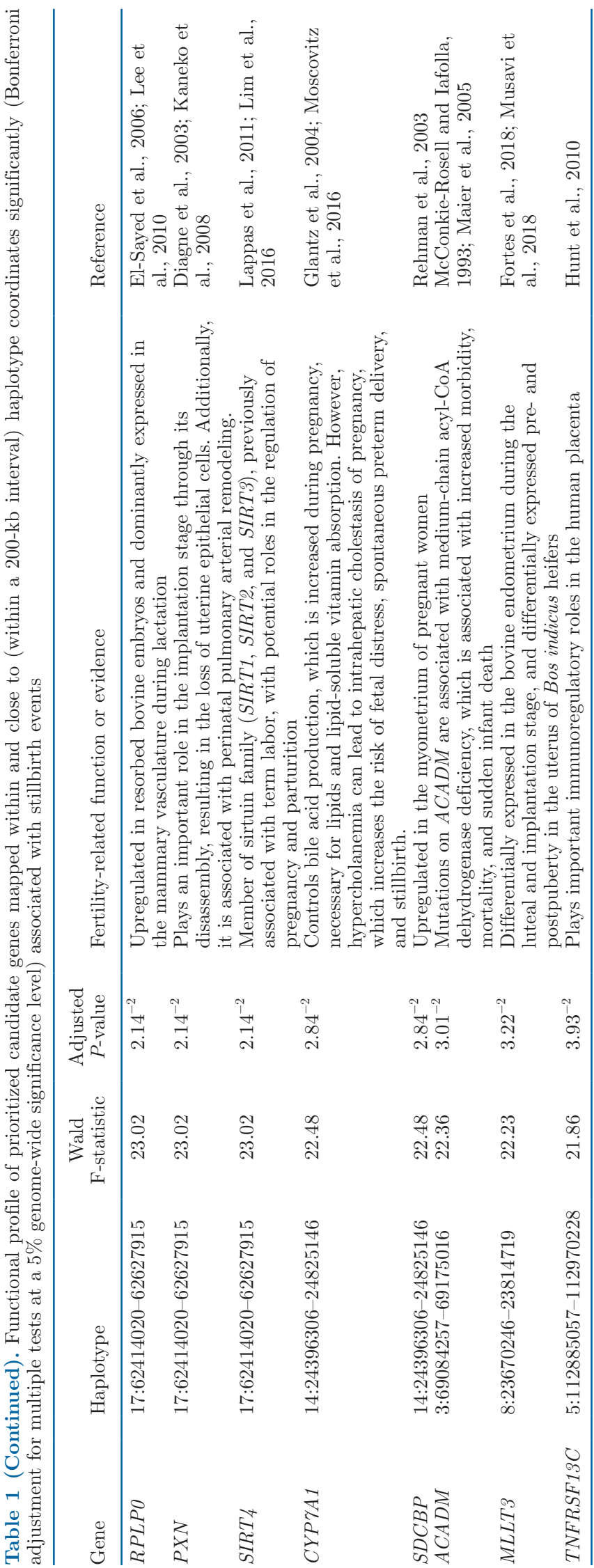

enriched (5 and 3, respectively; Table 2). Additionally, the relationship between the enriched fertility-related QTL, the haplotypes significantly associated with stillbirth, and the genes mapped within the haplotypes is shown in the Figure 5.

\section{DISCUSSION}

The top 5 significant functional candidate genes (HBS1L, PLG, MECOM, GRM1, and PEX3) mapped within the haplotype blocks related to pseudo-SNPs associated with stillbirth events play important roles related to fertility and the reproduction system. Among them, the HBS1L gene (HBS1 like translational GTPase) mapped within the coordinates of the most significant haplotype in BTA9 (BTA9:72923043-73175040). The $H B S 1 L$ gene is one of the main regulators of the fetal hemoglobin levels (Thein et al., 2007; Stadhouders et al., 2014). During pregnancy, fetal hemoglobin can leak into the maternal circulation, causing a spontaneous free oxygen radical accumulation, which is associated with preeclampsia in humans (Hansson et al., 2015). In addition, increased maternal hemoglobin levels are associated with higher risk of stillbirth (Lu et al., 1991; Blankson et al., 1993; Stephansson et al., 2000; Bhattarai et al., 2019).

The second most significant haplotype (BTA9: 96487958-96605772), also located on BTA9, mapped within the coordinates of the $P L G$ gene (plasminogen). The plasminogen activator system plays a crucial role in the degradation of intravascular thrombi and extracellular matrices (Vassalli et al., 1991). The PAI1 (plasminogen activators inhibitors 1) are the main inhibitors of these system and are responsible for inhibiting the trophoblast invasion during the pregnancy (Chakraborty et al., 2002). Mutations on PAI-1 are associated with female fertility diseases and worse pregnancy outcome, with recurrent pregnancy losses (Ye et al., 2017).

The MECOM gene (MDS1 and EVI1 complex locus) is mapped in the genomic region of the third most significant haplotype located on BTA1 (BTA1: 98318674-98615181) and is crucial for the long-term hematopoietic stem cell maintenance (Zhang et al., 2011). Mutations on the MECOM gene cause thrombocytopenia, abnormal low levels of platelets, and aplastic anemia (Nielsen et al., 2012; Niihori et al., 2015). The development of severe cases of thrombocytopenia during the pregnancy are associated with adverse perinatal outcomes, such as intrauterine growth restrictions and stillbirth in humans (Parnas et al., 2006). Additionally, $M E C O M$ seems to be essential for the distal segment and renal progenitor formation, which controls nephron multiciliate cells in zebrafish; consequently, this gene 
plays a crucial role in the embryo development ( $\mathrm{Li}$ et al., 2014).

The haplotype block mapped on BTA9: 83383631-83534942 harbors the GRM1 gene (glutamate metabotropic receptor 1 ), for which the gene product is called mGluR1. The expression of mGluR1 is predominantly postsynoptically in neuros of several structures of the central nervous system, such as hippocampus, hypothalamus, amygdala, among others (Shigemoto et al., 1992). The activation of the receptors for mGluR1, and another member of this family, mGluR5, results in a protective potential against periventricular leukomalacia in premature infants (Jantzie et al., 2010), which is a common abnormality found in brains of stillborns (Grafe and Kinney, 2002).

$\mathrm{a}$

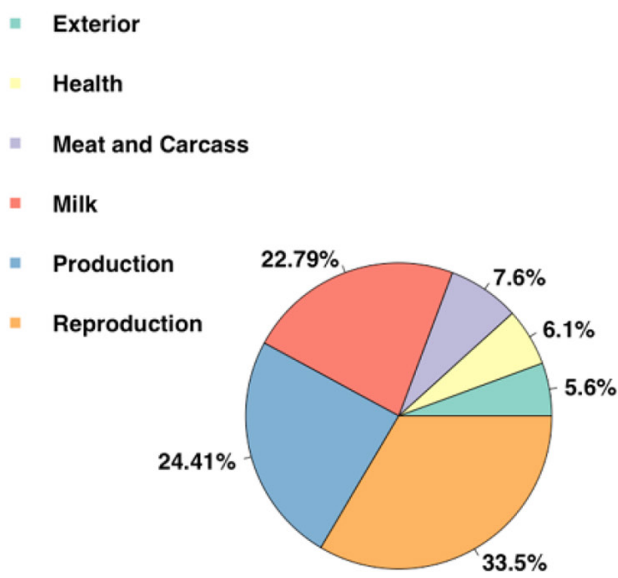

b

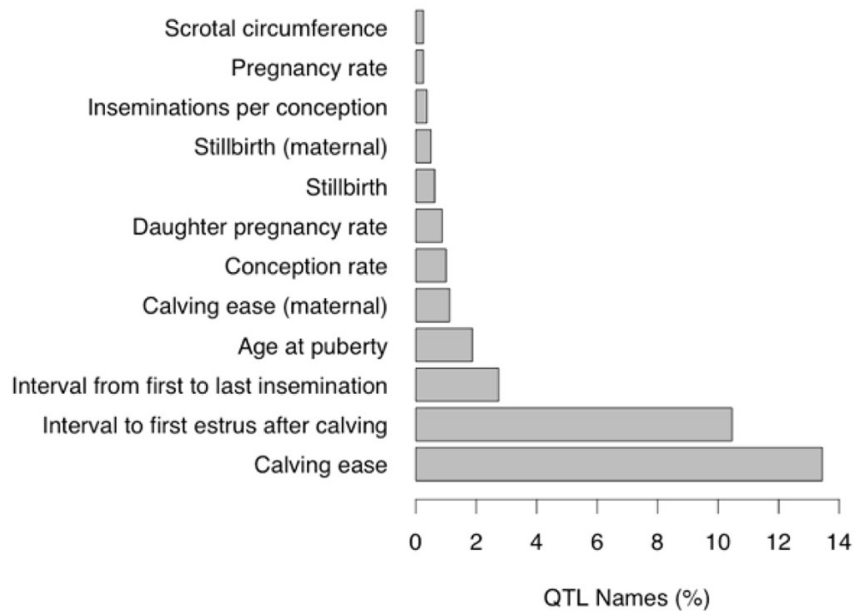

Figure 3. The QTL annotation within positional candidate haplotype blocks for stillbirth. (a) Percentage of each QTL class annotated within the 41 significantly ( $5 \%$ false discovery rate adjustment for multiple tests) associated pseudo-SNPs. (b) Contribution of each fertilityrelated trait for the total percentage of reproduction QTL (33.5\%).
Another significantly associated pseudo-SNP is located in the haplotype block mapped on BTA9: 80738394-81029512. This haplotype block harbors the PEX3 gene (peroxisomal biogenesis factor 3), which is responsible for peroxisomal membrane biogenesis (Matsui et al., 2013). Mutations on PEX3 are associated with the development of Zellweger syndrome, which is characterized by the deficiency to import peroxisomal matrix proteins (Baes et al., 1997). Interestingly, the occurrence of Zellweger syndrome is associated with stillbirth in humans (Wapner and Lewis, 2002).

Additionally, on top of the most significant genes described above, the other 26 functional candidate genes were also associated with relevant biological processes or phenotypes related to fertility. For example, the genes PCMTD1, NDUFB10, RPS2, SDCBD, and MLLT3 are differentially expressed in the endometrium of heifers in different conditions, such as in pre- and postpubertal stages (Rehman et al., 2003; Forde et al., 2012; Fortes et al., 2013, 2018; Killeen et al., 2014; Zhao et al., 2015; Mota et al., 2017; Musavi et al., 2018). In addition, GLDC, IFT57, AHI1, CACNA1C, GFER, RAB35, and $P X N$ were previously associated with the regulation of the embryonic development (Diagne et al., 2003; Valente et al., 2006; Kaneko et al., 2008; Todd et al., 2010; Narisawa et al., 2012; Fukuyama et al., 2014; Thevenon et al., 2016; Zhang et al., 2019; Strand et al., 2020). Interestingly, among the functional candidate genes, KDM4C, SYNJ2, DISC1, SLC9A3R2, TSC2, SIRT4, $C Y P^{7} 7 A 1$, and $A C A D M$ are associated with abortion, bad pregnancy outcomes, and early live death in different species (McConkie-Rosell and Iafolla, 1993; Glantz et al., 2004; Jablensky et al., 2005; Maier et al., 2005; Lappas et al., 2011; Lipina et al., 2013; Moscovitz et al., 2016; Lim et al., 2016; Sankar et al., 2017; Krieg et al., 2018; Kazmi et al., 2019; Jiang et al., 2020; Zhao et al., 2021).

It is important to highlight the relevance of BTA9 on the results obtained here. The smallest $P$-values were identified on this chromosome, as well as the largest number of functionally prioritized candidate genes (HBS1L, PLG, GRM1, PEX3, SYNJ2, and AHI1). Additionally, the QTL enrichment analysis reinforced the involvement of the genomic regions on BTA9 associated with stillbirth with fertility-related traits through an enrichment for conception rate and daughter pregnancy rate. The enrichment for other fertility-related QTL (interval to first estrus after calving, calving ease, age at puberty, pregnancy rate, and stillbirth) on genomic regions associated with stillbirth obtained in the present study reinforced the putative association of these candidate regions with fertility in dairy cattle. 


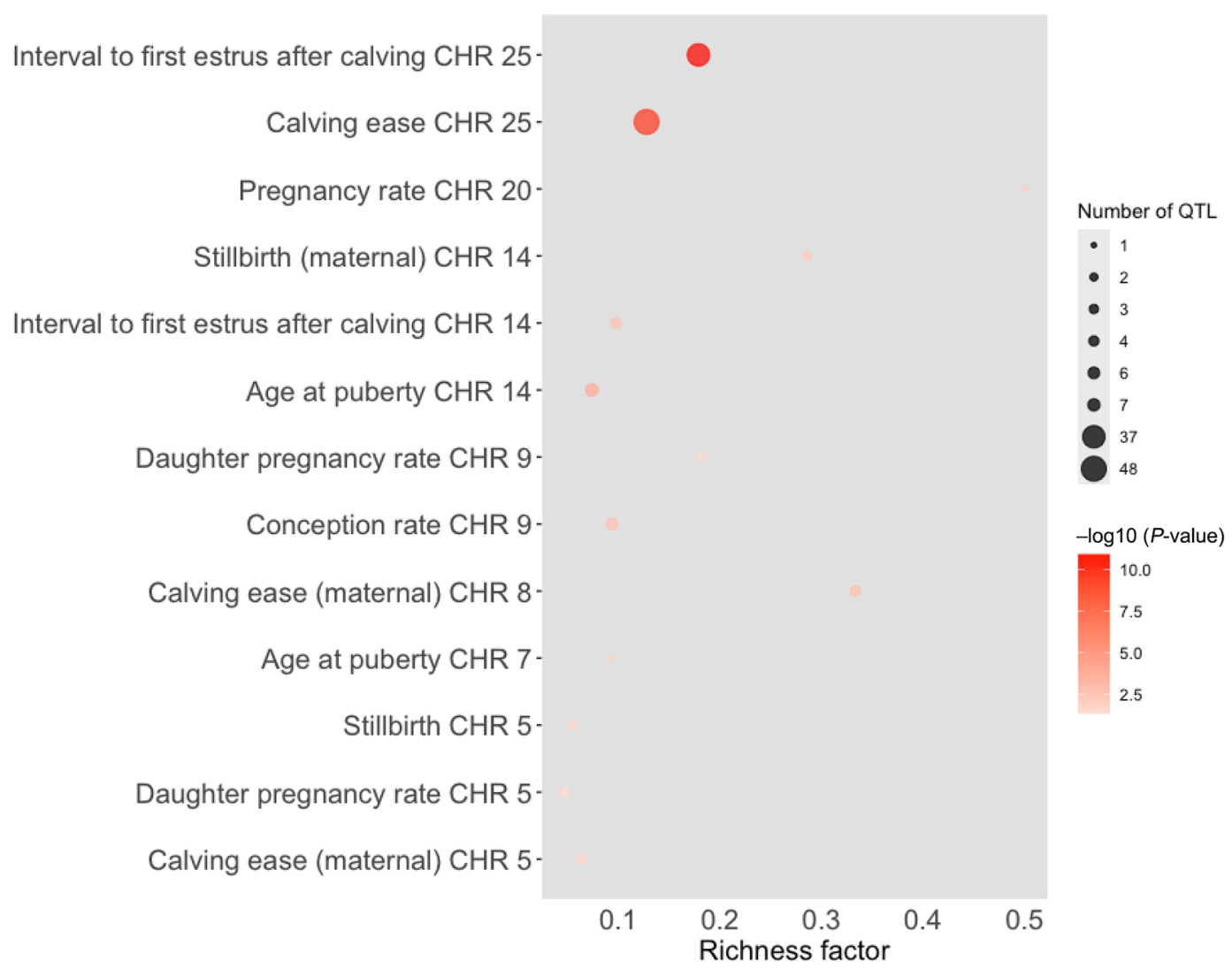

Figure 4. Bubble plot showing the enrichment results for the QTL annotated within the significant haplotypes after Bonferroni adjustment for multiple tests. The darker the color of the circle, the smaller the $P$-value; area of the circle corresponds to the number of QTL annotated. The $\mathrm{x}$-axis shows the richness factor, which is a ratio between the number of each QTL class annotated and the total number of that QTL class in the QTL database. $\mathrm{CHR}=$ chromosome.

The inclusion of other -omics technologies can be helpful to improve the detection power of genetic components associated complex traits, such as stillbirth, due to a larger proportion of the biological processes involved in the regulation and development of these phenotypes (Cánovas et al., 2014, 2017). Stillbirth is a complex trait with genetic and environmental components. In Canadian Holsteins, the heritability for this trait is quite low, ranging from 0.11 in first parities to 0.01 in later parities (Guarini et al., 2018). The data

Table 2. Enrichment analysis for QTL annotated within significant ( $5 \%$ false discovery rate adjustment for multiple tests) haplotypes after Bonferroni adjustment for multiple tests

\begin{tabular}{llcl}
\hline QTL & $\mathrm{CHR}^{1}$ & Number of QTL & $\mathrm{FDR}^{2}$ \\
\hline Interval to first estrus after calving & 25 & 37 & $1.28^{-11}$ \\
Calving ease & 25 & 48 & $5.18^{-10}$ \\
Age at puberty & 14 & 7 & 0.0002 \\
Calving ease (maternal) & 8 & 4 & 0.0023 \\
Conception rate & 9 & 6 & 0.0026 \\
Interval to first estrus after calving & 14 & 4 & 0.0028 \\
Stillbirth (maternal) & 14 & 2 & 0.0090 \\
Pregnancy rate & 20 & 1 & 0.0157 \\
Age at puberty & 7 & 3 & 0.0173 \\
Calving ease (maternal) & 5 & 3 & 0.0257 \\
Stillbirth & 5 & 2 & 0.0324 \\
Daughter pregnancy rate & 9 & 3 & 0.0385 \\
Daughter pregnancy rate & 5 & & 0.0432 \\
\hline
\end{tabular}

${ }^{1} \mathrm{CHR}=$ chromosome

${ }^{2} \mathrm{FDR}=$ false discovery rate. 


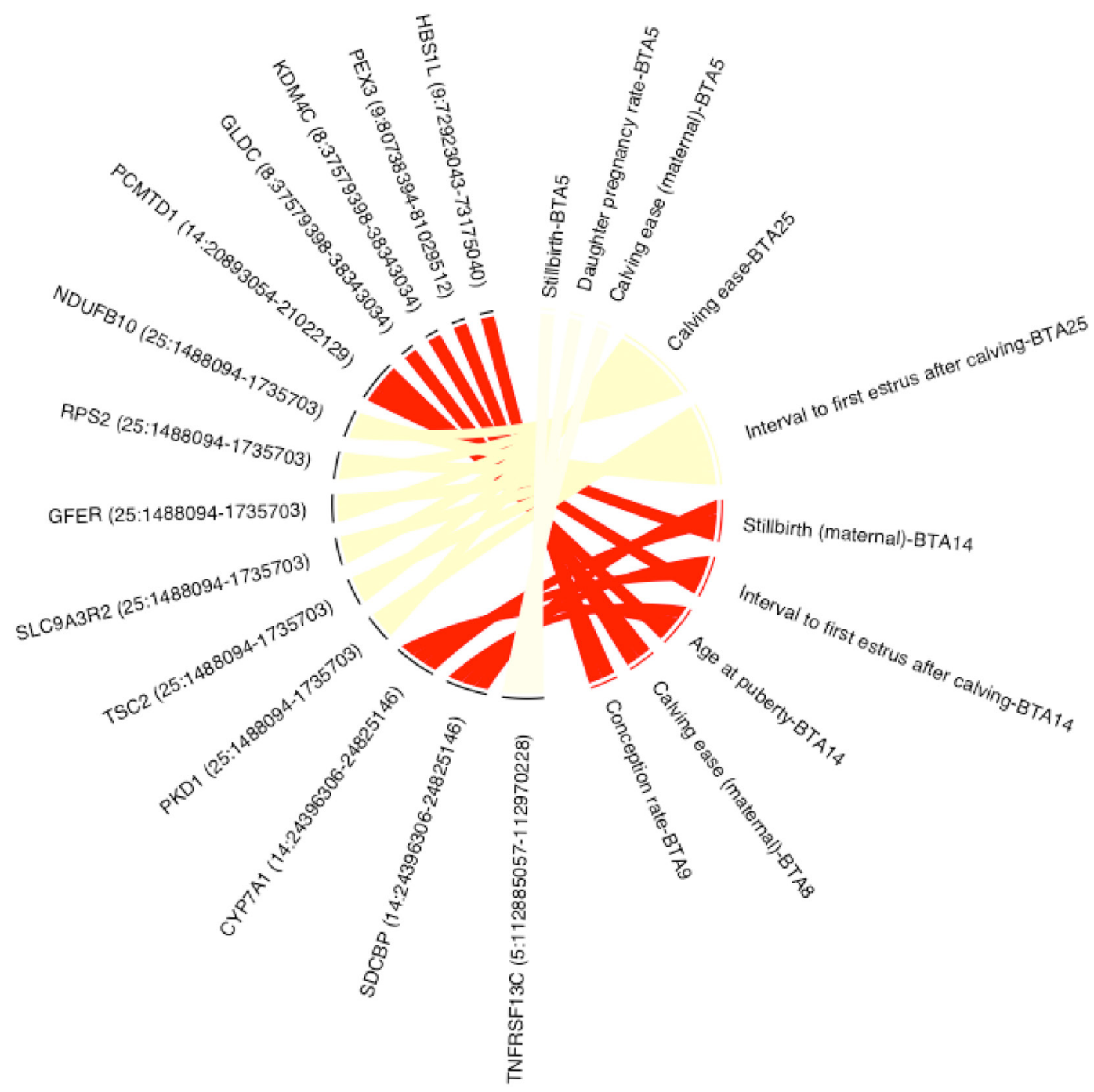

Figure 5. Chord plot showing the relationship between the prioritized functional candidate genes (left-hand side) and enriched fertilityrelated QTL (right-hand side). On the left-hand side, following gene names, in parentheses, are the coordinates of the significant haplotypes mapped to the genes. Darker colors in the chords connecting the genes and QTL represent smaller $P$-values associated with the haplotype in the GWAS for stillbirth.

set analyzed in the current study was obtained from the same population from which the abovementioned heritabilities were calculated. Due to this low heritability, usually only the records from the first parity are used for genetic evaluations. A satisfactory detection power was obtained with the model applied in the current study using multiple birth records from the same animal, which can be a more complete and helpful approach for GWAS and animal selection.

\section{CONCLUSIONS}

The prediction of stillbirth cases using genomic data can be helpful for the cattle industry due to the economic losses associated with this trait. The use of haplotype libraries combined with a repeated-records model in the GWAS showed to be an interesting alternative to use all available data to detect genomic regions associated with stillbirth in the cattle genome. In addition, the haplotypes significantly associated with stillbirth cases identified by the GWAS were annotated for positional functional candidate genes for reproductive performance. These genes play crucial roles in biological processes associated with pregnancy persistence, fetus development, and immune response, among others. The results reported here helped us to better understand the genetic basis of stillbirth in dairy cattle and may be useful for prediction of stillbirth in the Holstein cattle. 


\section{ACKNOWLEDGMENTS}

The authors acknowledge the funding for this study, which was supported by the Ontario Ministry of Agriculture, Food, and Rural Affairs (OMAFRA, Ontario, Canada), Ontario Ministry of Research and Innovation, Agriculture and Agri-Food Canada (AAFC, Ontario, Canada), and Natural Sciences and Engineering Research Council of Canada (NSERC, Ontario, Canada) Discovery Grant. This study (FDE.13.17) was also supported by the Sustainable Beef and Forage Science Cluster (Alberta, Canada) funded by the Canadian Beef Cattle Check-Off, Beef Cattle Research Council (BCRC), Alberta Beef Producers, Alberta Cattle Feeders' Association, Beef Farmers of Ontario, La Federation des Productuers de bovins du Quebec, and AAFC's Canadian Agricultural Partnership. This study is a part of the Food from Thought research program at the University of Guelph, which is funded in part by the Canada First Research Excellence Fund. The authors have not stated any conflicts of interest.

\section{REFERENCES}

Baes, M., P. Gressens, E. Baumgart, P. Carmeliet, M. Casteels, M. Fransen, P. Evrard, D. Fahimi, P. E. Declercq, D. Collen, P. P. Van Veldhoven, and G. P. Mannaerts. 1997. A mouse model for Zellweger syndrome. Nat. Genet. 17:49-57. https://doi.org/10.1038/ ng0997-49.

Barendse, W. 2011. Haplotype analysis improved evidence for candidate genes for intramuscular fat percentage from a genome wide association study of cattle. PLoS One 6:e29601. https://doi.org/10 .1371 /journal.pone.0029601.

Barrett, J. C., B. Fry, J. Maller, and M. J. Daly. 2005. Haploview: Analysis and visualization of LD and haplotype maps. Bioinformatics 21:263-265. https://doi.org/10.1093/bioinformatics/ bth457.

Bennewitz, J., N. Reinsch, S. Paul, C. Looft, B. Kaupe, C. Weimann, G. Erhardt, G. Thaller, C. Kühn, M. Schwerin, H. Thomsen, F. Reinhardt, R. Reents, and E. Kalm. 2004. The DGAT1 K232A mutation is not solely responsible for the milk production quantitative trait locus on the bovine chromosome 14. J. Dairy Sci. 87:431-442. https://doi.org/10.3168/jds.S0022-0302(04)73182-3.

Berglund, B., L. Steinbock, and M. Elvander. 2003. Causes of stillbirth and time of death in Swedish Holstein calves examined post mortem. Acta Vet. Scand. 44:111. https://doi.org/10.1186/1751 -0147-44-111.

Bhattarai, S., T. Framstad, and J. P. Nielsen. 2019. Association between sow and piglet blood hemoglobin concentrations and stillbirth risk. Acta Vet. Scand. 61:61. https://doi.org/10.1186/s13028 -019-0496-7.

Blankson, M. L., R. L. Goldenberg, G. Cutter, and S. P. Cliver. 1993. The relationship between maternal hematocrit and pregnancy outcome: Black-white differences. J. Natl. Med. Assoc. 85:130-4.

Cánovas, A., J. Casellas, M. Thomas, J. F. Medrano, and Associates. 2017. Applying new genomic technologies to accelerate genetic improvement in beef and dairy cattle. Pages 377-383 in Proc. Assoc. Advmt. Anim. Breed. Genet.

Cánovas, A., R. N. Pena, D. Gallardo, O. Ramírez, M. Amills, and R. Quintanilla. 2012. Segregation of regulatory polymorphisms with effects on the gluteus medius transcriptome in a purebred pig population. PLoS One 7:e35583. https://doi.org/10.1371/journal pone.0035583.
Cánovas, A., A. Reverter, K. L. DeAtley, R. L. Ashley, M. L. Colgrave, M. R. S. Fortes, A. Islas-Trejo, S. Lehnert, L. Porto-Neto, G. Rincón, G. A. Silver, W. M. Snelling, J. F. Medrano, and M. G. Thomas. 2014. Multi-tissue omics analyses reveal molecular regulatory networks for puberty in composite beef cattle. PLoS One 9:e102551. https://doi.org/10.1371/journal.pone.0102551.

Chakraborty, C., L. M. Gleeson, T. McKinnon, and P. K. Lala. 2002. Regulation of human trophoblast migration and invasiveness. Can. J. Physiol. Pharmacol. 80:116-124. https://doi.org/10.1139/y02 -016 .

Chen, J., E. E. Bardes, B. J. Aronow, and A. G. Jegga. 2009. ToppGene Suite for gene list enrichment analysis and candidate gene prioritization. Nucleic Acids Res. 37(Web Server):W305-311. https://doi.org/10.1093/nar/gkp427.

Chen, Z., Y. Yao, P. Ma, Q. Wang, and Y. Pan. 2018. Haplotype-based genome-wide association study identifies loci and candidate genes for milk yield in Holsteins. PLoS One 13:e0192695. https://doi .org/10.1371/journal.pone.0192695.

Diagne, I., S. M. Hall, S. Kogaki, C. M. Kielty, and S. G. Haworth 2003. Paxillin-associated focal adhesion involvement in perinatal pulmonary arterial remodelling. Matrix Biol. 22:193-205. https:// doi.org/10.1016/S0945-053X(03)00011-8.

El-Sayed, A., M. Hoelker, F. Rings, D. Salilew, D. Jennen, E. Tholen, M. A. Sirard, K. Schellander, and D. Tesfaye. 2006. Large-scale transcriptional analysis of bovine embryo biopsies in relation to pregnancy success after transfer to recipients. Physiol. Genomics 28:84-96. https://doi.org/10.1152/physiolgenomics.00111.2006.

Feitosa, F. L. B., A. S. C. Pereira, L. F. Mueller, P. A. S. Fonseca, C. U. Braz, S. Amorin, R. Espigolan, M. A. Lemos, L. G. de Albuquerque, F. S. Schenkel, L. F. Brito, N. B. Stafuzza, and F. Baldi. 2021. Genome-wide association study for beef fatty acid profile using haplotypes in Nellore cattle. Livest. Sci. 245:104396. https:/ /doi.org/10.1016/j.livsci.2021.104396.

Fonseca, P., A. Canovas, and F. Schenkel. 2021. JDS 20936: Genomewide association study using haplotype libraries and repeated measures model to identify candidate genomic regions for stillbirth in Holstein cattle. Mendeley Data, V1. https://doi.org/10.17632/ nnp5hdy9cv.1.

Fonseca, P. A. S., F. C. dos Santos, S. Lam, A. Suárez-Vega, F. Miglior, F. S. Schenkel, L. A. F. Diniz, S. Id-Lahoucine, M. R. S. Carvalho, and A. Cánovas. 2018. Genetic mechanisms underlying spermatic and testicular traits within and among cattle breeds: Systematic review and prioritization of GWAS results. J. Anim. Sci. 96:4978-4999. https://doi.org/10.1093/jas/sky382.

Fonseca, P. A. S. A. Suárez-Vega, and A. Cánovas. 2020a. Weighted gene correlation network meta-analysis reveals functional candidate genes associated with high- and sub-fertile reproductive performance in beef cattle. Genes (Basel) 11:543. https://doi.org/10 $.3390 /$ genes11050543.

Fonseca, P. A. S., A. Suárez-Vega, G. Marras, and Á. Cánovas. 2020b. GALLO: An R package for genomic annotation and integration of multiple data sources in livestock for positional candidate loci. Gigascience 9:giaa149. https://doi.org/10.1093/gigascience/giaa149.

Forde, N., J. P. Mehta, M. Minten, M. A. Crowe, J. F. Roche, T. E. Spencer, and P. Lonergan. 2012. Effects of low progesterone on the endometrial transcriptome in cattle. Biol. Reprod. 87. https://doi .org/10.1095/biolreprod.112.103424.

Fortes, M. R. S., Y. Li, E. Collis, Y. Zhang, and R. J. Hawken. 2013 The IGF1 pathway genes and their association with age of puberty in cattle. Anim. Genet. 44:91-95. https://doi.org/10.1111/j.1365 $-2052.2012 .02367 . x$

Fortes, M. R. S., L. F. Zacchi, L. T. Nguyen, F. Raidan, M. M. D. C. A. Weller, J. J. Y. Choo, A. Reverter, J. P. A. Rego, G. B. Boe-Hansen, L. R. Porto-Neto, S. A. Lehnert, A. Cánovas, B. L. Schulz, A. Islas-Trejo, J. F. Medrano, M. G. Thomas, and S. S. Moore. 2018. Pre- and post-puberty expression of genes and proteins in the uterus of Bos indicus heifers: The luteal phase effect post-puberty. Anim. Genet. 49:539-549. https://doi.org/10.1111/ age.12721

Fukuyama, M., Q. Wang, K. Kato, S. Ohno, W. G. Ding, F. Toyoda, H. Itoh, H. Kimura, T. Makiyama, M. Ito, H. Matsuura, and M. 
Horie. 2014. Long QT syndrome type 8: Novel CACNA1C mutations causing QT prolongation and variant phenotypes. Europace 16:1828-1837. https://doi.org/10.1093/europace/euu063.

Gabriel, S. B., S. F. Schaffner, H. Nguyen, J. M. Moore, J. Roy, B. Blumenstiel, J. Higgins, M. DeFelice, A. Lochner, M. Faggart, S. N. Liu-Cordero, C. Rotimi, A. Adeyemo, R. Cooper, R. Ward, E. S. Lander, M. J. Daly, and D. Altshuler. 2002. The structure of haplotype blocks in the human genome. Science 296:2225-2229. https://doi.org/10.1126/science.1069424.

Gilmour, A. R., B. J. Gogel, B. R. Cullis, S. J. Welham, and R. Thompson. 2015. ASReml User Guide: Release 4.1, Structural Specification. VSN Int. Ltd.

Glantz, A., H. U. Marschall, and L. Å. Mattsson. 2004. Intrahepatic cholestasis of pregnancy: Relationships between bile acid levels and fetal complication rates. Hepatology 40:467-474. https://doi .org/10.1002/hep.20336.

Grafe, M. R., and H. C. Kinney. 2002. Neuropathology associated with stillbirth. Pages 83-88 in Seminars in Perinatology. WB Saunders.

Guarini, A. R., D. A. L. Lourenco, L. F. Brito, M. Sargolzaei, C. F. Baes, F. Miglior, I. Misztal, and F. S. Schenkel. 2018. Comparison of genomic predictions for lowly heritable traits using multi-step and single-step genomic best linear unbiased predictor in Holstein cattle. J. Dairy Sci. 101:8076-8086. https://doi.org/10.3168/jds 2017-14193.

Guney, E., J. Garcia-Garcia, and B. Oliva. 2014. GUILDify: A web server for phenotypic characterization of genes through biological data integration and network-based prioritization algorithms. Bioinformatics 30:1789-1790. https://doi.org/10.1093/ bioinformatics/btu092.

Hansson, S. R., Å. Nääv, and L. Erlandsson. 2015. Oxidative stress in preeclampsia and the role of free fetal hemoglobin. Front. Physiol. https://doi.org/10.3389/fphys.2014.00516.

Hu, Z. L., C. A. Park, and J. M. Reecy. 2019. Building a livestock genetic and genomic information knowledgebase through integrative developments of Animal QTLdb and CorrDB. Nucleic Acids Res. 47(D1):D701-D710. https://doi.org/10.1093/nar/gky1084.

Hunt, J. S., J. L. Pace, and R. M. Gill. 2010. Immunoregulatory molecules in human placentas: Potential for diverse roles in pregnancy. Int. J. Dev. Biol. 54:457-467. https://doi.org/10.1387/ijdb $.082831 \mathrm{jh}$.

Id-Lahoucine, S., A. Cánovas, C. Jaton, F. Miglior, P. A. S. Fonseca, M. Sargolzaei, S. Miller, F. S. Schenkel, J. F. Medrano, and J. Casellas. 2019. Implementation of Bayesian methods to identify SNP and haplotype regions with transmission ratio distortion across the whole genome: TRDscan v.1.0. J. Dairy Sci. 102:3175-3188. https: //doi.org/10.3168/jds.2018-15296.

Jablensky, A. V., V. Morgan, S. R. Zubrick, C. Bower, and L. A. Yellachich. 2005. Pregnancy, delivery, and neonatal complications in a population cohort of women with schizophrenia and major affective disorders. Am. J. Psychiatry 162:79-91. https://doi.org/10 .1176/appi.ajp.162.1.79.

Jamrozik, J., A. Koeck, G. J. Kistemaker, and F. Miglior. 2016. Multiple-trait estimates of genetic parameters for metabolic disease traits, fertility disorders, and their predictors in Canadian Holsteins. J. Dairy Sci. 99:1990-1998. https://doi.org/10.3168/jds 2015-10505.

Jantzie, L. L., D. M. Talos, D. B. Selip, L. An, M. C. Jackson, R. D. Folkerth, W. Deng, and F. E. Jensen. 2010. Developmental regulation of group I metabotropic glutamate receptors in the premature brain and their protective role in a rodent model of periventricular leukomalacia. Neuron Glia Biol. 6:277-288. https://doi.org/10 .1017/S1740925X11000111.

Jiang, Y., S. Tang, W. Xiao, P. Yun, and X. Ding. 2020. A genomewide association study of reproduction traits in four pig populations with different genetic backgrounds. Asian-Australas. J. Anim. Sci. 33:1400-1410. https://doi.org/10.5713/ajas.19.0411.

Kaneko, Y., L. A. Lindsay, and C. R. Murphy. 2008. Focal adhesions disassemble during early pregnancy in rat uterine epithelial cells. Reprod. Fertil. Dev. 20:892. https://doi.org/10.1071/RD08148.

Kazmi, N., G. C. Sharp, S. E. Reese, F. O. Vehmeijer, J. Lahti, C. M. Page, W. Zhang, S. L. Rifas-Shiman, F. I. Rezwan, A. J. Simpkin,
K. Burrows, T. G. Richardson, D. L. Santos Ferreira, A. Fraser, Q. E. Harmon, S. Zhao, V. W. V. Jaddoe, D. Czamara, E. B. Binder, M. C. Magnus, S. E. Håberg, W. Nystad, E. A. Nohr, A. P. Starling, K. J. Kechris, I. V. Yang, D. L. DeMeo, A. A. Litonjua, A. Baccarelli, E. Oken, J. W. Holloway, W. Karmaus, S. H. Arshad, D. Dabelea, T. I. A. Sørensen, H. Laivuori, K. Raikkonen, J. F. Felix, S. J. London, M.-F. Hivert, T. R. Gaunt, D. A. Lawlor, and C. L. Relton. 2019. Hypertensive disorders of pregnancy and DNA methylation in newborns. Hypertension 74:375-383. https://doi .org/10.1161/HYPERTENSIONAHA.119.12634.

Killeen, A. P., D. G. Morris, D. A. Kenny, M. P. Mullen, M. G. Diskin, and S. M. Waters. 2014. Global gene expression in endometrium of high and low fertility heifers during the mid-luteal phase of the estrous cycle. BMC Genomics 15:234. https://doi.org/10.1186/ 1471-2164-15-234.

Krieg, A. J., S. R. Mullinax, F. Grimstad, K. Marquis, E. Constance, Y. Hong, S. A. Krieg, and K. F. Roby. 2018. Histone demethylase KDM4A and KDM4B expression in granulosa cells from women undergoing in vitro fertilization. J. Assist. Reprod. Genet. 35:9931003. https://doi.org/10.1007/s10815-018-1151-3.

Lam, S., F. Miglior, P. A. S. Fonseca, I. Gómez-Redondo, J. Zeidan, A. Suárez-Vega, F. Schenkel, L. L. Guan, S. Waters, P. Stothard, and A. Cánovas. 2021. Identification of functional candidate variants and genes for feed efficiency in Holstein and Jersey cattle breeds using RNA-sequencing. J. Dairy Sci. 104:1928-1950. https://doi .org/10.3168/jds.2020-18241.

Lappas, M., A. Mitton, R. Lim, G. Barker, C. Riley, and M. Permezel. 2011. SIRT1 is a novel regulator of key pathways of human labor. Biol. Reprod. 84:167-178. https://doi.org/10.1095/biolreprod.110 .086983 .

Lee, N. K., M. K. Kim, J. H. Choi, E. B. Kim, H. G. Lee, S. K. Kang, and Y. J. Choi. 2010. Identification of a peptide sequence targeting mammary vasculature via RPLP0 during lactation. Peptides 31:2247-2254. https://doi.org/10.1016/j.peptides.2010.09.008.

Lee, W., G. Costain, S. Blaser, S. Walker, C. R. Marshall, H. Gonorazky, and M. Inbar-Feigenberg. 2020. Genome sequencing identifies a rare case of moderate Zellweger spectrum disorder caused by a PEX3 defect: Case report and literature review. Mol. Genet. Metab. Rep. 25:100664. https://doi.org/10.1016/j.ymgmr.2020 .100664 .

Li, Y., C. N. Cheng, V. A. Verdun, and R. A. Wingert. 2014. Zebrafish nephrogenesis is regulated by interactions between retinoic acid, mecom, and notch signaling. Dev. Biol. 386:111-122. https://doi .org/10.1016/j.ydbio.2013.11.021.

Lim, R., G. Barker, R. Menon, and M. Lappas. 2016. A novel role for SIRT3 in regulating mediators involved in the terminal pathways of human labor and delivery1. Biol. Reprod. 95:95. https://doi .org/10.1095/biolreprod.116.142372.

Lipina, T. V., C. Zai, D. Hlousek, J. C. Roder, and A. H. C. Wong. 2013. Maternal immune activation during gestation interacts with Disc1 point mutation to exacerbate schizophrenia-related behaviors in mice. J. Neurosci. 33:7654-7666. https://doi.org/10.1523/ JNEUROSCI.0091-13.2013.

Lu, Z. M., R. L. Goldenberg, S. P. Cliver, G. Cutter, and M. Blankson. 1991. The relationship between maternal hematocrit and pregnancy outcome. Obstet. Gynecol. 77:190-194. https://doi.org/10 .1097/00006250-199102000-00005.

Mahnani, A., A. Sadeghi-Sefidmazgi, and H. Keshavarzi. 2018. Performance and financial consequences of stillbirth in Holstein dairy cattle. Animal 12:617-623. https://doi.org/10.1017/ S1751731117002026.

Maier, E. M., B. Liebl, W. Röschinger, U. Nennstiel-Ratzel, R. Fingerhut, B. Olgemöller, U. Busch, N. Krone, R. V. Kries, and A. A. Roscher. 2005. Population spectrum of ACADM genotypes correlated to biochemical phenotypes in newborn screening for medium-chain acyl-CoA dehydrogenase deficiency. Hum. Mutat. 25:443-452. https://doi.org/10.1002/humu.20163.

Martins de Carvalho, L., P. A. S. Fonseca, I. M. Paiva, S. Damasceno, A. S. B. Pedersen, D. Silva e Silva, C. E. Wiers, N. D. Volkow, and A. L. Brunialti Godard. 2020. Identifying functionally relevant candidate genes for inflexible ethanol intake in mice and humans 
using a guilt-by-association approach. Brain Behav. 10. https://doi org/10.1002/brb3.1879.

Matsui, S., M. Funahashi, A. Honda, and N. Shimozawa. 2013. Newly identified milder phenotype of peroxisome biogenesis disorder caused by mutated PEX3 gene. Brain Dev. 35:842-848. https:// doi.org/10.1016/j.braindev.2012.10.017.

McConkie-Rosell, A., and A. K. Iafolla. 1993. Medium-chain acyl CoA dehydrogenase deficiency: Its relationship to SIDS and the impact on genetic counseling. J. Genet. Couns. 2:17-27. https://doi.org/ 10.1007/BF00962557.

Moscovitz, J. E., B. Kong, K. Buckley, B. Buckley, G. L. Guo, and L. M. Aleksunes. 2016. Restoration of enterohepatic bile acid pathways in pregnant mice following short term activation of Fxr by GW4064. Toxicol. Appl. Pharmacol. 310:60-67. https://doi.org/10 .1016/j.taap.2016.08.021

Mota, R. R., S. E. F. Guimarães, M. R. S. Fortes, B. Hayes, F. F. Silva, L. L. Verardo, M. J. Kelly, C. F. de Campos, J. D. Guimarães, R. R. Wenceslau, J. M. Penitente-Filho, J. F. Garcia, and S. Moore. 2017. Genome-wide association study and annotating candidate gene networks affecting age at first calving in Nellore cattle. J. Anim. Breed. Genet. 134:484-492. https://doi.org/10 $.1111 /$ jbg. 12299

Musavi, S. A. A., S. Yamashita, T. Fujihara, H. Masaka, M. R. Islam, S. Kim, T. Gotoh, M. Kawahara, K. Tashiro, and N. Yamauchi. 2018. Analysis of differentially expressed genes and the promoters in bovine endometrium throughout estrus cycle and early pregnancy. Anim. Sci. J. 89:1609-1621. https://doi.org/10.1111/asj.13091.

Narisawa, A., S. Komatsuzaki, A. Kikuchi, T. Niihori, Y. Aoki, K. Fujiwara, M. Tanemura, A. Hata, Y. Suzuki, C. L. Relton, J. Grinham, K. Y. Leung, D. Partridge, A. Robinson, V. Stone, P. Gustavsson, P. Stanier, A. J. Copp, N. D. E. Greene, T. Tominaga, Y. Matsubara, and S. Kure. 2012. Mutations in genes encoding the glycine cleavage system predispose to neural tube defects in mice and humans. Hum. Mol. Genet. 21:1496-1503. https://doi.org/10 $.1093 / \mathrm{hmg} / \mathrm{ddr} 585$.

Nielsen, M., C. L. Vermont, E. Aten, C. A. L. Ruivenkamp, F. van Herrewegen, G. W. E. Santen, and M. H. Breuning. 2012. Deletion of the 3q26 region including the EVI1 and MDS1 genes in a neonate with congenital thrombocytopenia and subsequent aplastic anaemia. J. Med. Genet. 49:598-600. https://doi.org/10.1136/ jmedgenet-2012-100990.

Niihori, T., M. Ouchi-Uchiyama, Y. Sasahara, T. Kaneko, Y. Hashii, M. Irie, A. Sato, Y. Saito-Nanjo, R. Funayama, T. Nagashima, S. I. Inoue, K. Nakayama, K. Ozono, S. Kure, Y. Matsubara, M. Imaizumi, and Y. Aoki. 2015. Mutations in MECOM, encoding oncoprotein EVI1, cause radioulnar synostosis with amegakaryocytic thrombocytopenia. Am. J. Hum. Genet. 97:848-854. https://doi .org/10.1016/j.ajhg.2015.10.010.

Parnas, M., E. Sheiner, I. Shoham-Vardi, E. Burstein, T. Yermiahu, I. Levi, G. Holcberg, and R. Yerushalmi. 2006. Moderate to severe thrombocytopenia during pregnancy. Eur. J. Obstet. Gynecol. Reprod. Biol. 128:163-168. https://doi.org/10.1016/j.ejogrb.2005.12 .031 .

Pérez-Mancera, P. A., I. González-Herrero, K. Maclean, A. M. Turner, M. Y. Yip, M. Sánchez-Martín, J. L. García, C. Robledo, T. Flores, A. Gutiérrez-Adán, B. Pintado, and I. Sánchez-García. 2006. SLUG (SNAI2) overexpression in embryonic development. Cytogenet. Genome Res. 114:24-29. https://doi.org/10.1159/ 000091924.

Rehman, K. S., S. Yin, B. A. Mayhew, R. A. Word, and W. E. Rainey. 2003. Human myometrial adaptation to pregnancy: cDNA microarray gene expression profiling of myometrium from non-pregnant and pregnant women. Mol. Hum. Reprod. 9:681-700. https://doi .org/10.1093/molehr/gag078.

Sankar, A., S. M. Kooistra, J. M. Gonzalez, C. Ohlsson, M. Poutanen, and K. Helin. 2017. Maternal expression of the histone demethylase Kdm4a is crucial for pre-implantation development. Development 144:3264-3277. https://doi.org/10.1242/dev.155473.

Sargolzaei, M., J.P. Chesnais, and F.S. Schenkel. 2011. FImputeAn efficient imputation algorithm for dairy cattle populations. J. Dairy Sci. 89(E-Suppl. 1):421.
Shigemoto, R., S. Nakanishi, and N. Mizuno. 1992. Distribution of the mRNA for a metabotropic glutamate receptor (mGluR1) in the central nervous system: An in situ hybridization study in adult and developing rat. J. Comp. Neurol. 322:121-135. https://doi.org/10 $.1002 /$ cne.903220110.

Sitras, V., C. Fenton, and G. Acharya. 2015. Gene expression profile in cardiovascular disease and preeclampsia: A meta-analysis of the transcriptome based on raw data from human studies deposited in Gene Expression Omnibus. Placenta 36:170-178. https://doi.org/ 10.1016/j.placenta.2014.11.017.

Stadhouders, R., S. Aktuna, S. Thongjuea, A. Aghajanirefah, F. Pourfarzad, W. Van IJcken, B. Lenhard, H. Rooks, S. Best, S. Menzel, F. Grosveld, S. L. Thein, and E. Soler. 2014. HBS1L-MYB intergenic variants modulate fetal hemoglobin via long-range MYB enhancers. J. Clin. Invest. 124:1699-1710. https://doi.org/10.1172/ JCI71520.

Stephansson, O., P. W. Dickman, A. Johansson, and S. Cnattingius. 2000. Maternal hemoglobin concentration during pregnancy and risk of stillbirth. JAMA 284:2611. https://doi.org/10.1001/jama .284.20.2611.

Strand, S., J. F. Strasburger, B. F. Cuneo, and R. T. Wakai. 2020. Complex and novel arrhythmias precede stillbirth in fetuses with de novo long QT syndrome. Circ. Arrhythmia Electrophysiol. 13:e08082. https://doi.org/10.1161/CIRCEP.119.008082.

Sweett, H., P. A. S. Fonseca, A. Suárez-Vega, A. Livernois, F. Miglior, and A. Cánovas. 2020. Genome-wide association study to identify genomic regions and positional candidate genes associated with male fertility in beef cattle. Sci. Rep. 10:20102. https://doi.org/10 .1038/s41598-020-75758-3.

Thein, S. L., S. Menzel, X. Peng, S. Best, J. Jiang, J. Close, N. Silver, A. Gerovasilli, C. Ping, M. Yamaguchi, K. Wahlberg, P. Ulug, T. D. Spector, C. Garner, F. Matsuda, M. Farrall, and M. Lathrop. 2007. Intergenic variants of HBS1L-MYB are responsible for a major quantitative trait locus on chromosome 6q23 influencing fetal hemoglobin levels in adults. Proc. Natl. Acad. Sci. USA 104:11346-11351. https://doi.org/10.1073/pnas.0611393104.

Thevenon, J., L. Duplomb, S. Phadke, T. Eguether, A. Saunier, M. Avila, V. Carmignac, A. L. Bruel, J. St-Onge, Y. Duffourd, G. J. Pazour, B. Franco, T. Attie-Bitach, A. Masurel-Paulet, J. B. Rivière, V. Cormier-Daire, C. Philippe, L. Faivre, and C. ThauvinRobinet. 2016. Autosomal recessive IFT57 hypomorphic mutation cause ciliary transport defect in unclassified oral-facial-digital syndrome with short stature and brachymesophalangia. Clin. Genet. 90:509-517. https://doi.org/10.1111/cge.12785.

Todd, L. R., M. N. Damin, R. Gomathinayagam, S. R. Horn, A. R. Means, and U. Sankar. 2010. Growth factor erv1-like modulates Drp1 to preserve mitochondrial dynamics and function in mouse embryonic stem cells. Mol. Biol. Cell 21:1225-1236. https://doi .org/10.1091/mbc.e09-11-0937.

Valente, E. M., F. Brancati, J. L. Silhavy, M. Castori, S. E. Marsh, G. Barrano, E. Bertini, E. Boltshauser, M. S. Zaki, A. Abdel-Aleem G. M. H. Abdel-Salam, E. Bellacchio, R. Battini, R. P. Cruse, W. B. Dobyns, K. S. Krishnamoorthy, C. Lagier-Tourenne, A. Magee, I. Pascual-Castroviejo, C. D. Salpietro, D. Sarco, B. Dallapiccola, and J. G. Gleeson. 2006. AHI1 gene mutations cause specific forms of Joubert syndrome-related disorders. Ann. Neurol. 59:527-534. https://doi.org/10.1002/ana.20749.

Vassalli, J. D., A. P. Sappino, and D. Belin. 1991. The plasminogen activator/plasmin system. J. Clin. Invest. 88:1067-1072. https:// doi.org/10.1172/JCI115405.

Wapner, R. J., and D. Lewis. 2002. Genetics and metabolic causes of stillbirth. Pages 70-74 in Seminars in Perinatology. WB Saunders.

Wu, Y., H. Fan, Y. Wang, L. Zhang, X. Gao, Y. Chen, J. Li, H. Y. Ren, and H. Gao. 2014. Genome-wide association studies using haplotypes and individual SNPs in Simmental cattle. PLoS One 9:e109330. https://doi.org/10.1371/journal.pone.0109330.

Yamazaki, H., S. Kasai, J. Mimura, P. Ye, A. Inose-Maruyama, K. Tanji, K. Wakabayashi, S. Mizuno, F. Sugiyama, S. Takahashi, T. Sato, T. Ozaki, D. R. Cavener, M. Yamamoto, and K. Itoh. 2020. Ribosome binding protein GCN1 regulates the cell cycle and cell proliferation and is essential for the embryonic development of 
mice. PLoS Genet. 16:e1008693. https://doi.org/10.1371/journal .pgen.1008693.

Ye, Y., A. Vattai, X. Zhang, J. Zhu, C. J. Thaler, S. Mahner, U. Jeschke, and V. von Schönfeldt. 2017. Role of plasminogen activator inhibitor type 1 in pathologies of female reproductive diseases. Int. J. Mol. Sci. 18:1651. https://doi.org/10.3390/ijms18081651.

Zhang, P., B. C. McGrath, J. Reinert, D. S. Olsen, L. Lei, S. Gill, S. A. Wek, K. M. Vattem, R. C. Wek, S. R. Kimball, L. S. Jefferson, and D. R. Cavener. 2002. The GCN2 eIF2 $\alpha$ kinase is required for adaptation to amino acid deprivation in mice. Mol. Cell. Biol. 22:66816688. https://doi.org/10.1128/MCB.22.19.6681-6688.2002.

Zhang, Y., S. Stehling-Sun, K. Lezon-Geyda, S. C. Juneja, L. Coillard, G. Chatterjee, C. A. Wuertzer, F. Camargo, and A. S. Perkins. 2011. PR-domain-containing Mds1-Evi1 is critical for long-term hematopoietic stem cell function. Blood 118:3853-3861. https:// doi.org/10.1182/blood-2011-02-334680.

Zhang, Y., X. Wan, H. H. Wang, M. H. Pan, Z. N. Pan, and S. C. Sun. 2019. RAB35 depletion affects spindle formation and actin-based spindle migration in mouse oocyte meiosis. Mol. Hum. Reprod. 25:359-372. https://doi.org/10.1093/molehr/gaz027.
Zhao, C., H. Chai, Q. Zhou, J. Wen, U. M. Reddy, R. Kastury, Y. Jiang, W. Mak, A. E. Bale, H. Zhang, and P. Li. 2021. Exome sequencing analysis on products of conception: A cohort study to evaluate clinical utility and genetic etiology for pregnancy loss. Genet. Med. 23:435-442. https://doi.org/10.1038/s41436-020 $-01008-6$.

Zhao, H., L. Sui, K. Miao, L. An, D. Wang, Z. Hou, R. Wang, M. Guo, Z. Wang, J. Xu, Z. Wu, and J. Tian. 2015. Comparative analysis between endometrial proteomes of pregnant and non-pregnant ewes during the peri-implantation period. J. Anim. Sci. Biotechnol. 6:18. https://doi.org/10.1186/s40104-015-0017-0.

\section{ORCIDS}

P. A. S. Fonseca @ https://orcid.org/0000-0002-6917-7475

F. S. Schenkel (® https://orcid.org/0000-0001-8700-0633

A. Cánovas ํㅏ https://orcid.org/0000-0002-0036-0757 